\title{
Representatividade da população negra no material didático de geografia do programa "nova EJA": para além da denúncia, um outro olhar
}

Tiago Dionísio da Silva ${ }^{1}$

Guilherme Pereira Stribel ${ }^{2}$

\section{Resumo}

Este artigo apresenta uma análise do material didático de Geografia do Programa "Nova EJA" sobre como se dá a representatividade da população negra no referido material, uma vez que o segmento negro da sociedade brasileira é a maioria nos bancos escolares na EJA. A partir das análises chegamos aos seguintes resultados: o material ofertado, que se propõe inovador com vista a combater a defasagem entre idade/série e evasão escolar, precisa trazer em seu cerne uma nova concepção educacional em que a população negra se veja representada positivamente e, assim, incluída no sistema escolar, visto que a representação da população negra está negligenciada, estigmatiza e estereotipada, reforçando, assim, o racismo institucional no espaço escolar e colaborando para práticas pedagógicas racistas.

Palavras-chave: Educação de Jovens e Adultos Trabalhadores; Relações Raciais; Ensino de Geografia; Programa "Nova EJA"; Material Didático.

Representation of the Black Population in the didactic material of geography of the "Nova EJA" program: in addition to the complaint, another look

\section{Abstract}

This article presents an analysis of the didactic material of Geography of the "Nova EJA" Program on how the black population is represented in the referred material, since the black segment of Brazilian society is the majority in school banks in EJA. From the analysis we arrive at the following results: the material offered which proposes to be innovative in order to combat the gap between age / grade and school dropout, needs to bring at its core a new educational concept in which the black population is positively represented and thus, included in the school system, since the representation of the black population is neglected, stigmatizes and stereotyped, thus reinforcing institutional racism in the school space and collaborating for racist pedagogical practices.

Keywords: Education of Youth and Adult Workers; Racial Relations; Geography Teaching; "Nova EJA" Program; Courseware.

\section{Introdução}

A Nova Política para a Educação de Jovens e Adultos (Nova EJA), implantada no estado do Rio de Janeiro em 2013 sob a responsabilidade pedagógica do Centro de Ciências e Educação

\footnotetext{
${ }^{1}$ Programa de Pós-Graduação em Educação, Contextos Contemporâneos e Demandas da Universidade Federal Rural do Rio de Janeiro (PPGEduc/UFRRJ) e Secretaria de Estado de Educação do Rio de Janeiro (SEEDUC/RJ), Rio de Janeiro, tiago_dionisio@hotmail.com.br

2 Universidade Estácio de Sá (UNESA), Rio de Janeiro, stribelgp@gmail.com
} 
Superior a Distância do Estado do Rio de Janeiro (Fundação CECIERJ), impôs uma reestruturação curricular. Houve diminuição dos tempos diários de aula de 6 para 4, oferta de material didático específico para os professores e estudantes e formação continuada para os docentes com bolsa - esta destinada a custear as despesas como deslocamento e alimentação.

A reestruturação da EJA no estado fluminense aconteceu no bojo da mudança gerencial pela qual o Estado brasileiro vem passando na última década (ANDRADE, 2014; VENTURA, 2016), pois os resultados das avaliações - internas e externas à unidade escolar - e o índice de fluxo escolar foram baixos no ano de 2009, principalmente no Ensino Médio (EM). Assim, a Secretaria de Estado de Educação do Rio de Janeiro (SEEDUC/RJ) aprofundou suas ações através de programas diferenciados para obtenção de melhores resultados, como o "Nova EJA" voltado principalmente para o Ensino Médio.

Neste sentido, este artigo apresenta uma análise do material didático de Geografia com recorte para as relações raciais, mais especificamente como se dá a representatividade da população negra no referido material, uma vez que o segmento negro da sociedade brasileira é a maioria nos bancos escolares na EJA. Somado a isso, Miguel Gonzalez Arroyo (2007) denuncia que o sistema educacional brasileiro segue ações hierarquizadas e racializadas que implicam na exclusão de grande parte da população brasileira, neste caso, a negra; quando não, essa população está presente, porém invisibilizada política e didaticamente nas práticas pedagógicas e nos materiais didáticos. Logo, analisar o material ofertado pelo Programa Nova EJA, que se propõe inovador com vista a combater a defasagem entre idade/série e evasão escolar, precisa trazer em seu cerne uma nova concepção educacional em que a população negra se veja representada e, assim, incluída no sistema escolar.

Por material didático, aqui, entende-se os livros didáticos de Geografia dos estudantes. Michael Apple (1995, p.81) afirma que "os livros didáticos estabelecem grande parte das condições materiais para o ensino e a aprendizagem nas salas de aula de muitos países no mundo [...]. São os textos destes livros que frequentemente definem qual é a cultura legítima a ser transmitida." Então, vale indagar que cultura esses livros estão transmitindo? Que representatividade da população negra está posta? Uma vez que ela é o segmento populacional de maior presença nos bancos escolares da EJA.

Vale ressaltar que a história da população brasileira é marcada pelo racismo e pelo mito 
da democracia racial (HASENBALG, 2005; GOMES, 2005). Isso perpassará o sistema educacional e desembocará no "chão" da sala de aula de inúmeras maneiras: práticas pedagógicas racistas, invisibilidade do negro na história brasileira, reforço de estigmas e estereótipos dos estudantes negros. Tais práticas contribuirão para o que denominaremos apartheid escolar, ou seja, a população negra estará na escola, mas de maneira subalternizada e segregada.

Uma das principais ações dos movimentos negros no Brasil é atuar no sistema educacional para combater práticas racistas escolares. Essas práticas são, ao mesmo tempo, explícitas através de dados, mas muitas vezes camufladas por ações que se dizem inovadoras, mas que reforçam o racismo, como por exemplo o material didático do Programa "Nova EJA".

Sendo assim, este artigo está dividido em três partes: a primeira discute a origem e a proposta político-pedagógica do Programa "Nova EJA"; a segunda apresenta uma discussão teórica sobre a necessidade de reconfiguração da política pública da EJA e da Geografia Escolar que contemple os "novos sujeitos"; e a última parte traz análises da representação da população negra no material didático de Geografia do referido Programa.

\section{A Educação de Jovens e Adultos Trabalhadores no estado do Rio de Janeiro: considerações a partir do programa "Nova EJA"}

O Programa "Nova EJA" é fruto de um novo modelo de gestão que se pressupõe inovador e começou a ser implantado na Rede Estadual Pública de Ensino do Rio de Janeiro em 2009, após o referido estado ter amargado a penúltima colocação no ranking do Índice do Desenvolvimento da Educação Básica (IDEB).

O programa em análise resulta do conjunto de reformas realizadas pela SEEDUC-RJ após o ano de 2009 , em consequência imediata da penúltima colocação no ranking do Índice de Desenvolvimento da Educação Básica (IDEB). O mesmo insere-se no denominado "choque de gestão", como classificado pelo então secretário de educação do Estado do Rio de Janeiro Wilson Risolia, em entrevista ao jornal O Globo no dia 14 de agosto de 2012. Tal termo especificase, pela ótica do secretário, em melhorar a qualidade da educação do estado em comparação às demais unidades federativas, o que salienta a prerrogativa performática como primeira hipótese, vide o ranqueamento como indicativo qualitativo (ANDRADE, 2014, p.37). 
Nesse sentido, foram traçados estratégias e planejamento com o objetivo de melhorar a posição no ranking do IDEB. A pretensão do então Secretário de Educação, Wilson Risolia, era colocar o estado fluminense entre as cinco melhores Redes Públicas Estaduais do ranking do IDEB. ${ }^{3}$ Jaqueline Pereira Ventura assim se refere a esse processo:

Sob o argumento de que melhoraria a qualidade da educação do RJ e promoveria melhores resultados do desempenho escolar, a SEEDUC/RJ elaborou, em 2010, o planejamento estratégico para orientar a política estadual de educação. Esse modelo gerencial adotado definiu o modo de organização, o financiamento e a gestão das unidades escolares, pautando-se, principalmente, na Gestão Integrada na Escola (GIDE) e no Programa de Bonificação por Resultados. A meta era tornar o estado do Rio de Janeiro uma referência nacional de qualidade e eficiência na educação pública, com o objetivo imediato de elevar a posição da rede estadual no ranking do Índice de Desenvolvimento da Educação Básica (IDEB) (VENTURA, 2016, p.17).

Nesse processo, destacam-se algumas questões relacionadas ao baixo rendimento dos estudantes, a saber: falta de instrumento diagnóstico; falta de alinhamento ao currículo; aulas com baixa atratividade; alunos com dificuldade de aprendizagem; e elevada distorção idadesérie. Compreende-se a partir da argumentação da SEEDUC que o problema central da baixa qualidade da educação se relaciona com a ineficiência da gestão, pelo fato de não ser técnica, daí a justificativa para o "choque de gestão" e a implantação da Gestão Integrada da Escola.

O referido Programa nasce com o objetivo de sanar as inúmeras tentativas frustradas de políticas públicas voltadas para a EJA, de tornar a referida modalidade de ensino pedagogicamente mais dinâmica e atraente - combatendo a evasão, a defasagem idade/série, e de potencializar o direito à educação para os sujeitos historicamente excluídos do sistema escolar. A estrutura organizacional do "Nova EJA" é baseada em duas instâncias estaduais: a SEEDUC e a Secretaria de Estado de Ciência e Tecnologia (SECT). A SEEDUC ficou responsável pelos recursos humanos e pela infraestrutura física, ou seja, os docentes concursados ou contratados, as unidades escolares e a gestão dos discentes. Coube à SECT, por meio da Fundação CECIERJ/Consórcio CECIERJ, a organização curricular do referido Programa.

O Programa "Nova EJA" foi construído sob uma concepção de tecnologia educacional que

\footnotetext{
${ }^{3}$ De fato, isso ocorreu, pois o EM no estado fluminense saiu da 26ㅇp posição em 2009 para a 4ำ posição em 2013.
} 
objetivou reformular toda a estrutura curricular da EJA no estado fluminense. Essa reestruturação, segundo o Manual de Orientação do Programa Nova EJA, foi baseada em quatro pilares: 1) Material didático específico para o aluno; 2) Metodologia específica; 3) Roteirização de aula para o professor; 4) Formação continuada.

Outra inovação que o Programa trouxe foi explicitar o direito dos estudantes de 18 anos ou mais poderem se matricular na EJA EM, conforme está indicado no Art. 6으, observado o disposto no artigo 4ำ, inciso VII, da Lei no 9.394/96 - a idade mínima para matrícula em cursos de EJA de Ensino Médio, inscrição e realização de exames de conclusão de EJA do EM é 18 anos completos. Somado a isso, tornou-se obrigatória a matrícula dos estudantes com idade acima de 21 anos. Mesmo que os estudantes com essa idade quisessem optar pelo EM Regular, na hora de realizar a inscrição no sistema "Matricula Fácil", única forma de realizar a matricula, o próprio sistema, automaticamente, alocava os estudantes com mais de 21 anos nas turmas da EJA, fazendo, assim, uma triagem das turmas do EM Regular.

Ao analisar o "Nova EJA", estamos discutindo sobre um programa que alterou a matriz curricular, diminuiu os tempos de aula, estendeu o plano de curso de um ano e meio para dois anos e alternou as ofertas dos componentes curriculares em disciplinas com ênfase em Ciências Humanas e da Natureza, fragmentando ainda mais o currículo escolar. De acordo com a matriz curricular do programa,

Cada Módulo terá duração correspondente a 01 (um) semestre letivo, totalizando, para efeito de conclusão do Ensino Médio, em 4 (quatro) semestres letivos ou 2 (dois) anos. A carga horária diária de aulas, compreendida em turnos de 4 horas, será de 4 tempos de 50 minutos de aulas das disciplinas obrigatórias e 50 minutos para disciplinas optativas e dependência. No mesmo turno serão oferecidas aulas de Ensino Religioso ( $1 \times$ semana), Língua Estrangeira optativa ( 1 x semana) e dependência. Estas aulas, de 50 minutos, acontecem antes de iniciar o turno de aulas da EJA Ensino Médio, ou ao final entre um turno e outro (RIO DE JANEIRO, 2013a, p.8).

Segundo o manual de orientações, o curso é dividido em quatro módulos, divergindo da estrutura de anos e séries semestrais que vigoravam anteriormente. Cada módulo tem duração correspondente a um semestre letivo, totalizando, para efeito de conclusão do EM, quatro semestres letivos ou dois anos. A carga horária diária de aulas é de quatro tempos de 50 minutos 
para as disciplinas obrigatórias e 50 minutos para as disciplinas optativas. Ao longo dos quatros módulos, apenas as disciplinas de Língua Portuguesa, Matemática e Ensino Religioso são constantes. As demais ocorrem divididas entre os módulos. Para Ventura:

[...] a EJA, no nível médio, no RJ, mesmo que sob nova roupagem, continua sendo tratada pelo governo estadual, principal responsável por sua oferta, com uma concepção de suplência, de compensação e de correção de fluxo escolar (VENTURA, 2016, p.20).

Outra situação complexa é a questão da carga horária. Sob a justificativa de otimizar o tempo e viabilizar a permanência dos estudantes na escola, para a SEEDUC não fazia mais sentido ter seis tempos diários como era na "EJA Terminal", pois o primeiro tempo era desperdiçado, visto que os estudantes não o frequentavam. Nossa hipótese para essa situação concernente à ociosidade do primeiro tempo de aula (18h15min) se dá em função da mobilidade urbana, da questão do trabalho, entre outros fatores. Além disso, por causa do cansaço da jornada de trabalho e da periculosidade das cidades da Região Metropolitana, os discentes não ficavam até a última aula $(22 \mathrm{~h} 25 \mathrm{~min})$.

Como demonstra Ventura:

Essa concepção de EJA pautada em aceleração e correção do fluxo escolar é claramente expressa no Relatório de Gestão e Políticas Públicas de 2014, onde, segundo um organograma denominado Árvore de Soluções, para o problema de 'queda da distorção idade-série' a solução é 'Autonomia e Nova EJA' (SEEDUC, 2014, p.11). Em outras palavras, a EJA, no nível médio, no Rio de Janeiro, mesmo que sob nova roupagem, continua sendo tratada pelo governo estadual, principal responsável por sua oferta, com uma concepção de suplência, de compensação e de correção de fluxo escolar (VENTURA, 2016, p.20).

Esses problemas, na verdade, são problemas da educação brasileira como um todo, porém, quando analisados na EJA, tornam-se mais intensos e grandiosos, uma vez que esbarramos com as trajetórias escolares que já foram descontínuas por conta das mazelas do sistema capitalista, que impõe o abandono precoce da escola por muitos brasileiros devido ao ingresso no mundo do trabalho em prol da sua própria sobrevivência. Além disso, há a forte presença de estruturas escolares arcaicas que reforçam o racismo estrutural, o que não gera uma 
identificação dos estudantes com o ambiente escolar, provocando evasão e desinteresse pela escolarização.

\section{Ensino de Geografia e "novos sujeitos": reconfigurações políticas e quebra de paradigmas}

A Lei 10.639 - sancionada em 2003 pelo Presidente da República Luiz Inácio Lula da Silva -, que alterou a LDB de 1996 e instituiu a obrigatoriedade no EF e EM público e privado, do ensino de História e Cultura Africana e Afro-Brasileira, é fruto da luta dos movimentos negros. Tal luta se intensificou principalmente no século passado, com vistas a garantir a cultura africana e afro-brasileira nos currículos escolares com o fim de construir uma identidade entre os estudantes e o ambiente escolar. Sobre esse processo, Renato Emerson dos Santos destaca:

Em janeiro de 2003, foi promulgada a Lei 10639/03. Fruto de lutas históricas do movimento Negro brasileiro, as indicações contempladas pela Lei já apareciam no Congresso Nacional do Negro Brasileiro na década de 1950 - cujo documento final continha entre recomendações 'estimulo ao estudo das reminiscências africanas no país, bem como a remoção das dificuldades dos brasileiros de cor [...], e, posteriormente, nos anos de 1980, foi apresentada como Projeto de Lei na Constituinte de 1988 e sua aprovação reivindicada na Marcha Zumbi em 1995'. Sua aprovação visa alterar a Lei de Diretrizes e Bases da Educação, assumindo o papel do mundo da educação como fundamental na reprodução e na reversão do quadro de desigualdades raciais no Brasil (SANTOS, 2007, p.22).

Ainda que a Lei tenha determinado as áreas de Educação Artística, Literatura e História como componentes curriculares "carros-chefes" para a implantação dos seus objetivos, o que se propõe é a extensão para as demais áreas do currículo escolar, como a Geografia, por exemplo; e que esses objetivos sejam discutidos em todas as modalidades de ensino. Partindo dessa perspectiva, Gomes (2011) chama atenção para o lugar do debate sobre a questão racial nas diversas modalidades de ensino, em especial na EJA:

Nesse contexto, os níveis e as modalidades de ensino que antes contemplavam minimamente ou desconsideravam o impacto da dimensão étnico-racial na formação da nossa sociedade, nos destinos e trajetórias sociais e escolares dos negros e das negras são chamados para o debate. E a grande questão é: qual é o lugar ocupado pela questão racial na EJA? (GOMES, 2011, p.90). 
Debater a questão racial na EJA a partir da Geografia é relevante, pois a referida ciência busca enfrentar a posição e o reposicionamento dos indivíduos no mundo a partir do seu lugar, do seu território, do seu espaço geográfico mediados pelas configurações e reconfigurações construídas a partir de relações complexas e estruturadas pelas questões sociais, culturais, econômicas e raciais.

A vida do estudante da EJA é atravessada por inúmeras questões sociais, culturais, econômicas e raciais. Assim, a raça, como elemento que regula as relações sociais no Brasil, de alguma forma tem suas manifestações e tensões grafadas no espaço geográfico brasileiro. Com isso, queremos dizer que os jovens e adultos e, por consequência, a população negra não ocupam qualquer território desse espaço. Esses sujeitos são estrategicamente empurrados para as favelas e periferias, onde a presença dos aparelhos estatais é precária, bens culturais escassos, transportes públicos deficitários. Essas análises são inerentes à Geografia e, portanto, ao ensino dela. Por isso, seu ensino deve atentar para o fato de que emergem as desigualdades socioeconômicas e raciais materializadas no espaço.

Trazer a Geografia para o centro do debate sobre raça e racismo como elementos estruturantes da sociedade brasileira impõe um desafio ao pensar o seu próprio ensino, considerando essas temáticas complexas e até então pouco exploradas. A Geografia e, por extensão, o seu ensino - ao problematizar, refletir e construir novas análises, tendo como ponto de partida a questão racial - constroem-se deixando de ser uma mera disciplina de caráter enciclopédico e europeizado, passando a ser uma forma, também, de desvendar o racismo e seus impactos sociais, além de contribuir para construção de visões de mundo comprometidas com a igualdade social. Santos reforça que:

Uma reflexão acerca da inserção da temática racial no ensino de Geografia torna forçoso, portanto, uma reflexão acerca do(s) sentido(s) de aprender/ensinar Geografia, pois é o sentido, enquanto manifestação de visões de mundo e de projetos societários, que orienta a práxis, é ele que vai definir a forma como tal temática é (ou não) abordada (SANTOS, 2007, p.25-26).

Sendo a Geografia a ciência que estuda o espaço construído pelos seres humanos, é preciso considerar que esses seres humanos tem uma raça e que essa condição racial - por meio do racismo - foi um elemento fundamental para que impusessem a ele um lugar espacial e social. 
Recorrendo novamente a Santos (2007):

Buscando inspiração em tais formulações, propomos aqui a ideia de que o sentido do aprender e ensinar a Geografia é se posicionar no mundo. Quando falamos isso, estamos indicando na verdade uma dupla acepção do que chamamos 'se posicionar no mundo': (i) conhecer sua posição no mundo, e para isto o indivíduo precisa conhecer o mundo; (ii) tomar posição neste mundo, que significa se colocar politicamente no processo de construção e reconstrução deste mundo. Se posicionar no mundo é, portanto, conhecer a sua posição no mundo e tomar posição neste mundo, agir. Saber Geografia é saber onde você está, conhecer o mundo, mas isto serve fundamentalmente para você agir sobre este mundo no processo de reconstrução da sociedade: se apresentar para participar (SANTOS, 2007, p.27, grifos do autor).

Partindo desses pressupostos, vale compreender que, "as ciências vêm sendo desafiadas diante de fenômenos e processos de grandes envergaduras que o mundo vem experimentando, sobretudo nos últimos 40 anos" (PORTO-GONÇALVES, 2007, p.7). Nesse sentido, tal reconfiguração imprime, também, a reconfiguração das ciências, em nosso caso específico, da ciência geográfica, pois ela foi originada em um eurocentrismo que escravizou os africanos, exterminou os povos indígenas e oprimiu os pobres. Como destaca Carlos Walter Porto-Gonçalves:

Quanto às ciências ditas humanas os desafios não são menores. Para perder o fio com o anterior considere-se o fato de que as ciências humanas não podem mais continuar a ignorar a inscrição material da sociedade na natureza por meio do espaço geográfico. Mas não param por aí os desafios. Grandes fenômenos e processos sociais colocam os paradigmas hegemônicos das ciências sociais em questão como, por exemplo, a queda do muro de Berlim e, sobretudo, a emergência de novos protagonistas reivindicando o 'direito a ter direitos' como mulheres, os povos originários e os afro-latino-americanos. [...] As ciências humanas, inclusive as ciências híbridas como a Geografia, não estavam preparadas para a emergência desses movimentos. Antes de tudo porque continuam prisioneiras do eurocentrismo e não conseguem analisar criticamente o significado da noção de modernidade e, assim, tornam essa noção um fundamentalismo (PORTO-GONÇALVES, 2007, p.8-9).

Esses fenômenos aos quais o autor se refere como promotores da quebra de paradigma das ciências têm intrínseca relação à EJA. Desse modo, reconfigurar a EJA como um espaço público, democrático e de direito significa conectar-se às mudanças que vêm ocorrendo no mundo. São dois lados de uma mesma moeda, pois, assim como as ciências humanas são 
colocadas em xeque - porque ao olhar para a "história da EJA, essas vivências foram interpretadas politicamente como opressão, como negação da liberdade, como desumanização" (ARROYO, 2011, p.41) -, do mesmo modo implicaram em uma reconstrução, visto que "a educação desses jovens e adultos foi assumida como um ato político como exercício de emancipação e libertação" (ARROYO, 2011, p.41).

Assim, é necessário refletirmos sobre uma Geografia que abarque essas novas demandas, levando em conta que a questão racial tem um protagonismo a ser considerado nesse debate, visto que ao longo da história brasileira a população negra ficou à margem dos direitos sociais. Além disso, ao longo do tempo as análises geográficas não incorporaram as reivindicações do povo negro, pois "o sistema mundo moderno-colonial, e sua Geografia, se conformou por meio da discriminação racial" (PORTO-GONÇALVES, 2007, p.11). Dito de outro modo, mas, nas palavras do mesmo, autor:

Não olvidemos que a África que temos hoje não é o resultado da história dos povos africanos somente, mas a história da subordinação, exploração, diáspora que constituiu a formação geográfica daquele continente, sobretudo depois da subordinação imposta pelos europeus por meio de seus conquistadores, religiosos e negociantes. A Geografia, quando liberta do eurocentrismo começa a deixar falar as relações sociais e de poder que conforme o espaço assimétrico do sistema mundo moderno-global (PORTO-GONÇALVES, 2011, p.10).

Tal situação não tem reflexo somente no Brasil, mas é uma guinada de concepções e mudanças conceituais e paradigmáticas que acontecem mundialmente, no sentido que tem repercussão na educação a partir de inspirações das lutas reivindicatórias país afora. PortoGonçalves (2007) aponta, ainda, a intrínseca relação entre os movimentos negros, a educação e a Geografia e, no mesmo sentido, Mônica Lima (2006) defende a importância do continente africano para a humanidade:

E ainda devemos lembrar que a História da África é parte indissociável da história da humanidade, na sua expressão mais completa. A África é o berço da humanidade, lá surgiram as primeiras formas gregárias de vida dos homens e mulheres no nosso planeta. Em toda sua longa história, os nativos do continente africano estiveram relacionando-se aos habitantes de outras regiões e continentes. Seus conhecimentos, produtos, criações e ideias circularam o mundo, assim como seus criadores (LIMA, 2006, p.74). 
Se dentro da própria Geografia existe uma crise de paradigmas - tanto no âmbito acadêmico como no âmbito escolar -, essa crise não é um privilégio exclusivo da Ciência Geográfica, ou seja, ela é, segundo Arroyo, desdobramento dos acontecimentos no setor educacional e da pressão social pelo qual o mundo está passando. Para o referido autor,

Reações semelhantes, encontramos nas escolas: políticas educacionais, de um lado, e nas campanhas como todos pela educação, toda criança na escola, democratização da educação infantil 4-5 anos e universalização (quase) do Ensino Fundamental de novos anos. De outro lado, as reprovações, retenções, defasagens idade-série, a separação das turmas de alunos exitosos, de um lado, e repetentes, defasados, desacelerados, indisciplinados, de outro. As classificações de alunos, de escola privada vs pública, de qualidade vs sem qualidade estão mais fortes com a chegada dos (as) filhas (as) dos trabalhadores empobrecidos, das periferias e dos campos. As formas de pensar essas infâncias e adolescências e de pensar os diferentes se tornaram mais duras, mais negativas na medida em que se fazem mais presentes e afirmativos, lutando por direitos (ARROYO, 2012, p.122).

Todo esse rearranjo impõe novas posturas científicas frente a esses novos sujeitos e suas demandas. Essa situação coloca em xeque a produção do conhecimento e o modo de se produzir ciência e seus desdobramentos com foco na sala de aula. Entretanto, de que maneira esses conhecimentos sistematizados têm contribuído para a dissolução dessa crise construída por esses "novos sujeitos"? Como a Pedagogia está lidando com isso? Como a Geografia incluiu essas novas reivindicações? Segundo Arroyo, estamos diante de um cenário complexo e, nesse sentido, o autor questiona:

Por que as presenças dos diferentes se tornam um incomodo e provocam reações de controle? Porque como diferentes propõem outro projeto de campo, de cidade e de sociedade, de escola e de universidade. Porque se contrapõem a apropriação/expropriação da terra e do espaço, a exploração do trabalho e a destruição da agricultura camponeses, da produção de alimentos para a vida. A diversidade de lutas e de ações coletivas populares e de movimentos sociais mexe nas estruturas e relações mais brutais de dominação/subordinação dos trabalhadores, dos setores populares. Trazendo as lutas para o direito à terra, teto, moradia, trabalho, vida, escola, universidade, instalam os direitos nos núcleos estruturantes das relações políticas de dominação/subordinação. Da produção-reprodução das desigualdades. A reação política a esses movimentos expõe a radicalidade política que eles trazem para as relações políticas e econômicas, culturais e pedagógicas (ARROYO, 2012, p.122). 
E no bojo dos movimentos sociais reivindicatórios temos as lutas dos movimentos negros pelo reconhecimento das desigualdades raciais no Brasil, até então invisibilizadas pelo mito da democracia racial que impera em nosso país. Assim, os aspectos da população negra não eram levados em conta e muito menos reconhecidos, devido à falácia de que todos são iguais, passíveis de se desenvolveram e ascenderem social e economicamente. Sales Augusto Santos alerta que

\begin{abstract}
Embora existam estudos que demonstrem a responsabilidade da escola na perpetuação das desigualdades sociais, como, por exemplo, Bourdieu (1998), não há dúvidas de que para os negros a busca da instrução (educação formal) como fator de integração socioeconômica e competição com os brancos, logo após a abolição da escravatura, foi um passo correto; porém, não suficiente para a sua ascensão social. Os negros compreenderam que sem educação formal dificilmente poderiam ascender socialmente, ou seja, obter mobilidade vertical individualmente ou coletivamente, numa sociedade em pleno processo de modernização (SANTOS, 2005, p.22).
\end{abstract}

Nessa perspectiva, a escola passa a ter um enorme valor para os negros, pois eles enxergaram na educação formal uma estratégia para ascenderem socialmente. Então, a partir daí, o espaço escolar vem recebendo "novos sujeitos", antes à margem desse mesmo espaço. Porém, o fato de eles estarem presentes, ao longo do tempo, não significou que eram compreendidos como parte de uma sociedade. Simplesmente o sistema escolar os absorveu, mas não garantiu que suas especificidades socioeconômicas, políticas e culturais fossem incorporadas ao seu universo. Assim, “[...] a escola ou a educação formal não foi e nem é a panaceia para os negros brasileiros. Logo a militância e os intelectuais negros descobriram que a escola também tem responsabilidade na perpetuação das desigualdades raciais" (SANTOS, 2005, p.22).

Germán Wettstein (2005) nos convida a refletir sobre que geografia ensinar, considerando "[...] o mundo tal qual ele é (e não tal qual ele foi)" (WETTSTEIN, 2005, p.126), pois esses "novos sujeitos" reconfiguraram o mundo como o conhecemos, revelando algo ainda não enxergado, ou melhor, algo que é negligenciado. Isso implica em uma nova educação, em uma nova escola, em uma nova prática pedagógica e, por consequência, em um novo olhar geográfico que contemple a questão racial.

Já não é mais possível educar como educávamos. As disputas no campo político do mundo exterior batem à porta da escola e obrigam essa instituição a se reconfigurar e com ela toda sua 
cultura, pois a escola abriga pobres, negros, quilombolas, mulheres, homossexuais, indígenas, trabalhadores urbanos, rurais, uma gama de religiões, saberes, vivencias e experiências, como o demonstra Arroyo:

No momento em que os setores populares repolitizam o papel dessas representações inferiorizadas ao longo da história da sua segregação, subordinação e negação de seus direitos, o campo das representações sociais passa a ser um dos campos de disputa política, mas também pedagógica. As formas de pensar os educandos condicionam as formas de educá-los. Condicionam o pensamento pedagógico. As teorias pedagógicas não ficam à margem dessas tensões, nem as políticas, os currículos, nem a cultura escolar e docente. São pressionadas a repensar as representações dos educandos e dos coletivos populares com que trabalham nas escolas, na EJA, na educação popular. As lógicas estruturantes do sistema escolar são pressionadas a se repensar. A cultura política tão segregadora é obrigada a se repensar (ARROYO, 2012, p.125).

Na visão de Wettstein (2005), a Geografia precisa dar conta de conteúdos tradicionais, mas também se preocupar não mais como o mundo era, mas sim como o mundo está hoje. Além disso, como o mundo mudou, o espaço geográfico mudou também e, consequentemente, os sujeitos produtores desse espaço geográfico não ficaram isentos a essa mudança.

Contribuindo para o debate, Nídia Nacib Pontuschka, Tomoko lyda Paganelli e Núria Hamglei Cacete destacam:

\begin{abstract}
A Geografia, como ciência, avançou em seus vários ramos, e deveria ter havido uma contribuição maior para seu ensino e aprendizagem. No entanto, é preciso lembrar que o movimento e o ritmo de mudanças nas sociedades se alteraram, as relações internacionais se mundanizaram e se globalizaram, o neoliberalismo se expediu e vem, de forma profunda, interferindo no cotidiano de nossas vidas e também no cotidiano escolar. Na atualidade, tais transformações exigem urgentemente a criação de respostas como novos conteúdos. Os conteúdos convencionais intrínsecos à Geografia precisam ser vistos por novos prismas (PONTUSCHKA et al., 2007, p.26).
\end{abstract}

Assim, a Geografia precisa reconfigurar suas bases didático-pedagógicas no sentido de atender a esses "novos sujeitos". Pontuschka aponta a necessidade de ter como ponto de partida a condição de existência desses alunos, pois 
As condições de existência dos próprios alunos e seus familiares são ponto de partida e de sustentação que podem garantir a compreensão do espaço geográfico, dentro de um processo que vai do particular ao geral e retorna enriquecido ao particular. Enfim, propiciar aos alunos a vivência de um método de trabalho que possa ser usado em diferentes situações, para que eles, gradativamente, adquiram autonomia no processo de produção do conhecimento, é um aspecto importante que o educador deve buscar (PONTUSCHKA, 2005, p.133).

Nesse sentido, mais uma vez reiteramos a importância da Geografia na discussão da questão racial, pois "as relações raciais grafam o espaço, se constituem no espaço e com o espaço. Revelar estas espacialidades é tarefa da Geografia” (SANTOS, 2015, p.321), pois

[...] uma sociedade que constituiu suas relações por meio do racismo, [...][tem] em sua Geografia lugares e espaços com marcas dessa distinção social: no caso brasileiro, a população negra é francamente majoritária nos presídios e absolutamente minoritária nas universidades; [...] essas diferentes configurações espaciais se constituem em espaços de conformação das subjetividades de cada qual. Enfim, há toda uma série de sujeitos sociais cuja compressão da sua própria natureza sociológica implica considerar o espaço e a natureza - camponeses, os indígenas, os afrodescentes (com seus palenques, na Colômbia e na Venezuela, e seus quilombos no Brasil) os ecologistas, os moradores, os jovens-da-periferia (hip-hop), para não dizer do próprio operariado (PORTO-GONÇALVES, 2002, p.4 apud SANTOS, 2007, p.29).

Depreendemos da citação acima que, se o racismo estruturou a sociedade brasileira, também organizou o espaço geográfico brasileiro. A população negra não ocupa qualquer espaço, pois "[...] a organização especializada das relações raciais constrói aquilo que Sansone chamou de 'espaços negros' e 'espaços brancos', na verdade, atribuições subjetivas de princípios valorativos a contextos e espaços" (SANTOS, 2015, p.328).

O espaço geográfico evidencia a acumulação desigual verificada através do tempo, possibilitando-nos análises a partir das relações raciais que configuraram esse espaço no passado e no presente. Assim, é possível observarmos as marcas espaciais da desigualdade racial no Brasil produzidas pelo período escravocrata e pelos movimentos migratórios pós-Abolição. A segregação racial se materializa nos surgimentos dos bairros, das periferias, das favelas espalhadas pelas cidades brasileiras, demarcando e expressando o lugar social e espacial da população negra. 
[...] Os bairros e comunidades de maioria negra que temos hoje são, portanto, heranças do passado e também fruto do racismo no presente, que aparece como um regulador de acessos diferenciados a oportunidades sociais de renda, emprego, educação e também (consequentemente) moradia, grafando o espaço urbano como constituinte de um modelo capitalista periférico, dependente e baseado na hiperexploração da força de trabalho (SANTOS, 2015, p.333).

Vale ressaltar que a raça não marca somente o espaço geográfico brasileiro, nem estrutura a sociedade, ela interfere também na cultura e na identidade enquanto nação, pois "[...] os estudos e as pesquisas sobre relações raciais, assim como a luta política do Movimento Negro, têm nos mostrado que, no contexto do racismo brasileiro, a 'raça' ganha mais destaque do que a língua ou a religião" (SILVEIRO, 2002, p.226 apud GOMES, 2011, p.98). Sendo assim, "[...]os processos de EJA e o campo das políticas públicas terão que se abrir para esse debate ao focalizarem a juventude e as pessoas adultas" (SILVEIRO, 2002, p.226 apud GOMES, 2011, p.98).

A Geografia pode desvelar as dimensões e desigualdades espaciais marcadas pela desigualdade social, mas também racial. Construir análises comprometidas não só com a denúncia, mas com a luta pela igualdade de direitos, agregando às suas análises as condições sociais, econômicas e raciais dos sujeitos presentes nas salas de aula da EJA. Levando em conta não somente as ausências, mas ressignificando as lutas de resistência, a cultura, as marcas sociais e espaciais produzidas por essa população que vem ao longo dos séculos lutando pela igualdade de condições.

\section{Representação da população negra no material didático de Geografia do programa "Nova EJA": desconstruções de estigmas e estereótipos}

Tendo como foco o material didático de Geografia do "Nova EJA", composto por 4 volumes, sendo 2 volumes referentes ao módulo 1, quando os discentes têm 4 tempos de Geografia; e 2 volumes do módulo 3, quando os estudantes têm 3 tempos de Geografia, observamos assim, a intensa fragmentação curricular ${ }^{4}$, uma vez que os módulos impares são baseados nas ciências humanas e os pares, nas ciências da natureza. Vale informar que esse material não foi construído

\footnotetext{
${ }^{4}$ Para maiores informações consultar a Matriz da (Nova) EJA Ensino Médio disponível no manual de orientações do Nova EJA, disponível no link: http://projetoseeduc.cecierj.edu.br/eja/manual-eja.pdf
}

Periódico Horizontes - USF - Itatiba, SP - Brasil - e020067 
em parceria com os docentes que atuavam no chão da escola e é composto de manuais para professores feitos pelos tutores conteudistas, que por sua vez foram contratados pela Fundação CECIERJ.

Ressaltamos que foram analisados os 4 volumes do material de Geografia, porém apresentaremos as discussões somente dos volumes 1 e 2 do módulo 1 , pois os volumes 1 e 2 do módulo $3^{5}$, apesar de trazerem conteúdos que poderiam discutir facilmente a questão racial no seu interior, não foram identificadas nenhuma imagem, dados ou assunto que fizessem alusão a população negra, o que aponta para um verdadeiro "apagão" das relações raciais durante um módulo inteiro.

Quadro 1: Conteúdo do módulo 1, volume 1

\begin{tabular}{|c|c|c|}
\hline UNIDADES & TEMAS & SEÇÕES \\
\hline 1 & $\begin{array}{l}\text { Construção do espaço } \\
\text { geográfico - p.7 }\end{array}$ & $\begin{array}{l}\text { 1) O Espaço Geográfico - p.9 } \\
\text { 2) Paisagem - p.10 } \\
\text { 3) Território - p.13 } \\
\text { 4) Lugar - p.15 }\end{array}$ \\
\hline 2 & Espaço e Fronteira - p.25 & $\begin{array}{l}\text { 1) A importância das fronteiras e dos territórios - p.26 } \\
\text { 2) As fronteiras ontem e hoje - p.28 } \\
\text { 3) Os espaços de conflito - p.34 } \\
\text { 4) Espaço de solidariedade - p.47 }\end{array}$ \\
\hline 3 & $\begin{array}{l}\text { Regionalização Fluminense: o } \\
\text { Rio de Janeiro em foco - p.61 }\end{array}$ & $\begin{array}{l}\text { 1) Conhecendo a regionalização brasileira e } \\
\text { fluminense - p.63 } \\
\text { 2) A influência do contexto histórico e } \\
\text { socioeconômico na configuração regional - p. } 75\end{array}$ \\
\hline 4 & $\begin{array}{l}\text { Redescobrindo a cartografia - } \\
\text { p.99 }\end{array}$ & $\begin{array}{l}\text { 1) Um pouco mais de história ... - p.102 } \\
\text { 2) Elementos básicos para a compreensão dos mapas - } \\
\text { p.111 } \\
\text { 3) Identificando cartograficamente o estado do Rio de } \\
\text { Janeiro - p.130 } \\
\text { 4) Cartografia e as novas tecnologias - p.133 }\end{array}$ \\
\hline
\end{tabular}

Fonte: http://projetoseeduc.cecierj.edu.br/eja/material-aluno/modulo01/Miolo_Ciencias_Humanas_Mod01_Vol01_Nova_eja_Aluno.pdf

No volume 1, pertencente ao módulo 1, apesar de temas pertinentes às categorias analíticas da ciência geográfica, bem como a cartografia enquanto linguagem, os conteúdos relacionados à população negra não são abordados, nem mesmo como exemplificação da

\footnotetext{
${ }^{5}$ Volume 1: unidade 1 - A indústria e suas transformações socioeconômicas; unidade 2 - Sociedade em Redes, modelos, atores e lugares no mundo globalizado; unidade 3 - A questão energética no mundo contemporâneo. Volume 2: unidade 1 - Ambiente e dinâmica da paisagem: climas e biomas; unidade 2 - Dinâmica Ambiental: relevo e hidrografia; unidade 3 - Meio ambiente e sociedade.
} 
aplicabilidade de algum conceito. A ausência do tratamento dessas questões vai de encontro ao que Vazoller aponta:

[...] o estudo da Geografia pode debater, no interior de uma instituição escolar, uma infinidade de questões, entre elas, as raciais, a partir do objeto de estudo dessa disciplina, que é a produção do espaço, construído por diferentes povos, com todos os seus conflitos e tensões (VAZOLLER, 2006, p.174).

Deste modo, observamos um material que não dialoga com a realidade da maioria dos alunos da EJA. O que se vê é uma geografia comprometida com a técnica, com o domínio da teoria descolada da realidade do estudante. Tal situação gera - para além de uma análise não completa do espaço geográfico onde os estudantes da EJA estão inseridos - uma geografia colonizada, desconsiderando a situação de mais da metade da população brasileira que, no último censo demográfico realizado pelo IBGE, em 2010, tornou-se majoritária.

Que identidade esses estudantes terão com esse material didático? Como eles farão a conexão com sua vida prática? Qual a representatividade que construirão? São questões que os agentes envolvidos com a educação, neste caso, a EJA, devem pensar e se questionar, para que tal situação não seja mais um dos fatores que proporcionam a evasão desses sujeitos já excluídos por diversas vezes do sistema escolar formal.

Somente na seção 3 (os espaços de conflito) - que está dentro da unidade 2 (Espaço e Fronteira) -, que aborda as principais disputais territoriais, é que teremos um conteúdo ligado à população negra. Entretanto, é uma abordagem feita de forma totalmente desequilibrada, visto que primeiro serão abordados os conflitos no território europeu, depois no continente asiático e, por fim, na África. Vale destacar que, em 13 páginas dedicadas ao assunto, o continente africano ocupa apenas a metade de uma página, sem mapas e ilustrações, apenas uma discussão superficial sobre os conflitos que lá ocorrem. Portanto, temos um desequilíbrio didáticopedagógico através de uma opção política de invisibilizar as relações intrínsecas que existem entre o continente africano e a sociedade brasileira.

Essa lacuna conteudista, essa ausência curricular sobre temas relacionados à população negra impede os alunos de conhecerem z sua própria condição humana, problematizá-la e ressignificá-la a partir dos conhecimentos técnico-científicos e filosóficos que a escola discute. 
Nesse sentido, os estereótipos e estigmas são reforçados, tendo um impacto negativo na vida dos estudantes pretos e pardos, e perpetuando, assim, o racismo escolar que se estende à sociedade como um todo.

Quadro 2: Conteúdo do módulo 1, volume 2

\begin{tabular}{|c|c|c|}
\hline UNIDADES & TEMAS & SEÇÕES \\
\hline 1 & $\begin{array}{l}\text { A distribuição desigual dos } \\
\text { indicadores de qualidade de } \\
\text { vida no espaço brasileiro e } \\
\text { mundial - p.7 }\end{array}$ & $\begin{array}{l}\text { 1) A população brasileira no Censo } 2010 \text { - p.9 } \\
\text { 2) Um Brasil de desigualdades - p.10 } \\
\text { 3) O Índice de Desenvolvimento Humano - IDH - p.11 } \\
\text { 4) Desigualdades: condições de vida no campo e na } \\
\text { cidade - p.18 }\end{array}$ \\
\hline 2 & $\begin{array}{l}\text { Dinâmica Populacional e } \\
\text { Mobilidade Humana: motivos, } \\
\text { causas e consequências - p.27 }\end{array}$ & $\begin{array}{l}\text { 1) A Transição Demográfica e a Estrutura Etária de } \\
\text { uma População - p.29 } \\
\text { 2) Pessoas em movimento pelo mundo: a chamada } \\
\text { mobilidade humana - p.37 } \\
\text { 3) Mobilidade humana no Brasil - p.43 } \\
\text { 4) Causas e efeitos da mobilidade humana - p.48 }\end{array}$ \\
\hline 3 & $\begin{array}{l}\text { Cidade e qualidade de vida - } \\
\text { p.63 }\end{array}$ & $\begin{array}{l}\text { 1) O mundo cada vez mais urbano - p.67 } \\
\text { 2) As migrações para as cidades - p.77 } \\
\text { 3) O espaço urbano e suas desigualdades - p.82 } \\
\text { 4) É possível pensar em uma cidade mais justa e } \\
\text { igualitária? - p.84 }\end{array}$ \\
\hline 4 & $\begin{array}{l}\text { Espaço rural e diversidade } \\
\text { socioespacial - p.99 }\end{array}$ & $\begin{array}{l}\text { 1) O rural ao longo da história - p.101 } \\
\text { 2) Vamos diferenciar o mundo rural? - p.106 } \\
\text { 3) E o campo se moderniza... - p.117 } \\
\text { 4) Agropecuária e estrutura fundiária brasileira p.123 }\end{array}$ \\
\hline
\end{tabular}

Fonte: http://projetoseeduc.cecierj.edu.br/eja/material-aluno/modulo01/Miolo_Ciencias_Humanas_Mod01_Vol02_Nova_eja_Aluno.pdf

$\mathrm{Na}$ abertura da unidade 1 do volume 2, que trata sobre a distribuição desigual dos indicadores de qualidade de vida no espaço brasileiro e mundial (para iniciar a discussão sobre o tema), há um trecho de reportagem sobre os dados do Censo demográfico de 2010, apresentando o resultado que demonstra a população negra como sendo majoritária no território brasileiro. Entretanto, a abordagem deixa a desejar: apenas é feita uma apresentação sem nenhuma problematização do assunto. Vejamos: 
Figura 1: Trecho de reportagem que consta na página 8.

Veja alguns dos resultados publicados sobre o Censo 2010.

IBGE aponta aumento de brasileiros que se declaram pardos ou pretos

Soma de ambos os grupos representam 50,7\% de toda populaçâa; brancos não são mais maioria.

(Estado de S. Paulo, 22 de julho de 2011)

Fonte: http://projetoseeduc.cecierj.edu.br/eja/material-aluno/modulo-

01/Miolo_Ciencias_Humanas_Mod01_Vol02_Nova_eja_Aluno.pdf

Apenas apresentar essa informação sem nenhuma discussão sobre o aumento da população negra na sociedade brasileira é negligenciar toda uma história de luta e resistência que está por trás desses dados. Além disso, um dado estático, apenas numérico, retira a força do aluno de compreender as reais condições que os homens e as mulheres possuem em nossa sociedade. Logo, temos uma Geografia Tradicional que tem por premissa ser "apolítica". Os avanços numéricos representam um aumento de autoafirmação da negritude, mas só isso não basta para empoderar a discussão em torno das relações raciais.

O que nós, professores, podemos fazer para que, a partir do estudo da geografia, nossos alunos conheçam a condição humana dos negros, descubram seu próprio valor como agente ativo na sociedade e adquiram capacidade de analisar criticamente o tratamento desigual que é dispensado aos negros? Primeiramente, abordar esses aspectos não significa inventar novos conteúdos; propõe-se, antes, que ao discutir os conceitos e conteúdos oferecidos pela geografia, o professor rompa com abordagem tradicional dos temas a serem estudados (VAZOLLER, 2006, p.175).

É, no mínimo, preocupante esta situação, uma vez que os materiais didáticos acabam sendo o guia dos conteúdos utilizados por inúmeros professores. Além disso, são os recursos didáticos que mais chegam aos discentes, portanto, é necessário estar explícito no material temas geográficos com discussões que tenham o recorte racial, para que não fique somente a critério da mediação do professor fazê-lo ou não.

Seguindo a discussão sobre a ausência de questões étnico-raciais no conteúdo de Geografia, na unidade 1, seção 3 (O Índice de Desenvolvimento Humano - IDH), também não se discutem as condições materiais de vida da população negra. Ademais, existe um apagamento 
da presença do homem negro, da mulher negra e das crianças negras ao ilustrar uma temática que busca discutir diretamente os aspectos sociais da vida, mas traz somente uma imagem que, em relação a questões raciais, não quebra paradigmas, muito menos reconfigura a prática pedagógica em Geografia.

Figura 2: Imagem que ilustra o assunto sobre IDH na página 14.

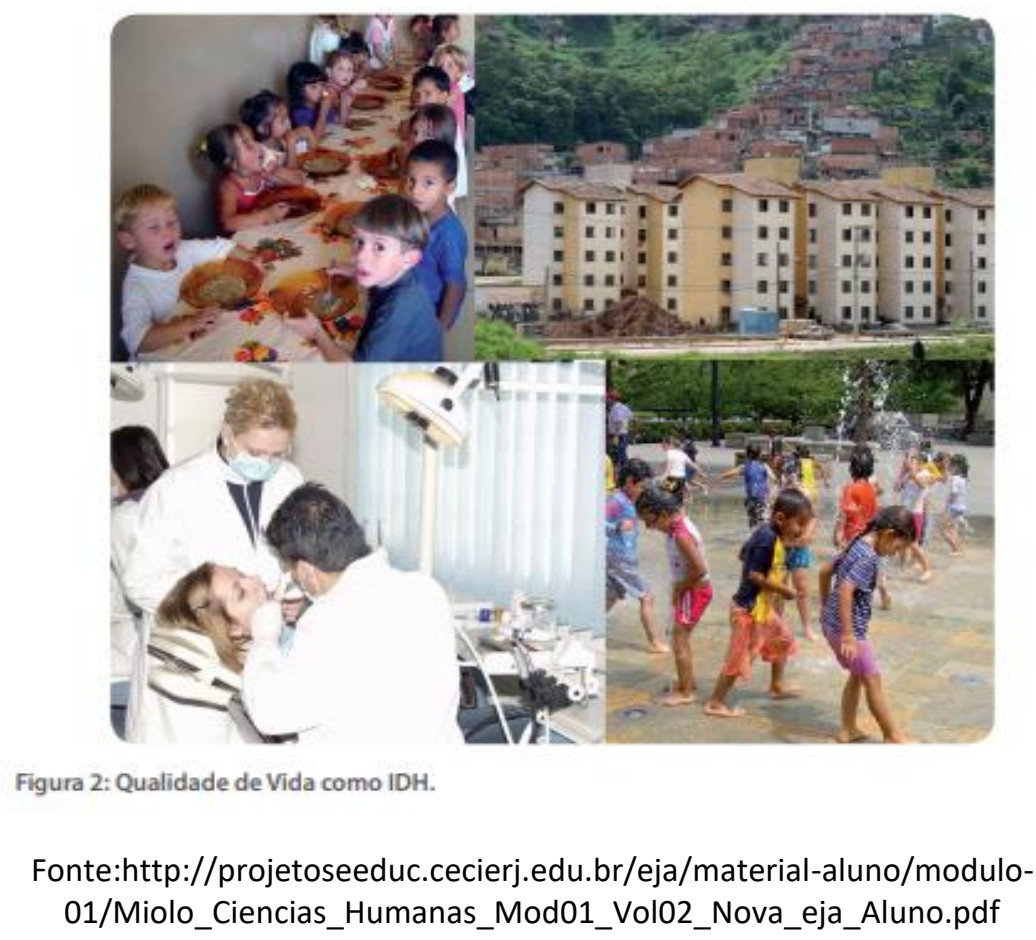

Determinados conteúdos geográficos que constam nas diretrizes curriculares já possuem em si o recorte racial, como o estudo da população. "Entendemos que a geografia é a ciência da sociedade que busca decifrá-la à luz de suas realizações espacialmente definidas" (CARVALHO, 1994, p.81), porém, a partir da imagem acima, é possível questionar: em que lugar a população negra se encontra? Será que ela está tão à margem que sequer merece ser representada? Qual o impacto da ausência do recorte racial, situação que por inúmeras vezes repetida pode influenciar na autoestima dos discentes negros, em especial na EJA, onde são a maioria?

Uma outra situação problemática encontrada no material analisado diz respeito à ilustração que retrata o negro de forma negativa. Quanto a isso, não é necessário negar que os fatores históricos colocaram a população negra em situação desigual socioeconomicamente. 
Sendo assim, em um material que representa o negro pelo viés da ausência ou precariedade, sem uma abordagem positiva, faz-se necessário uma maior discussão sobre a imagem abaixo, algo que ainda não ocorreu satisfatoriamente. Portanto, fica mais uma vez a critério do professor fazer essa intervenção, que poderá ocorrer ou não.

Figura 3: Exemplificação das condições de vida no campo e na cidade na página 19

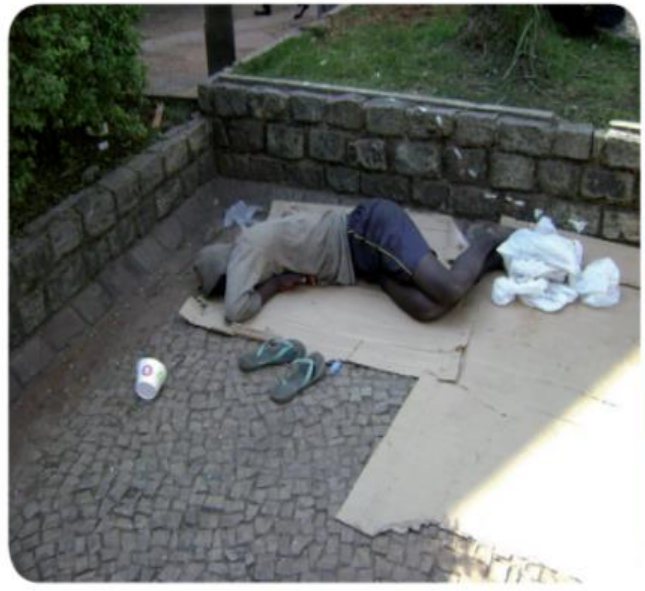

Morador de rua de Belo Horizonte

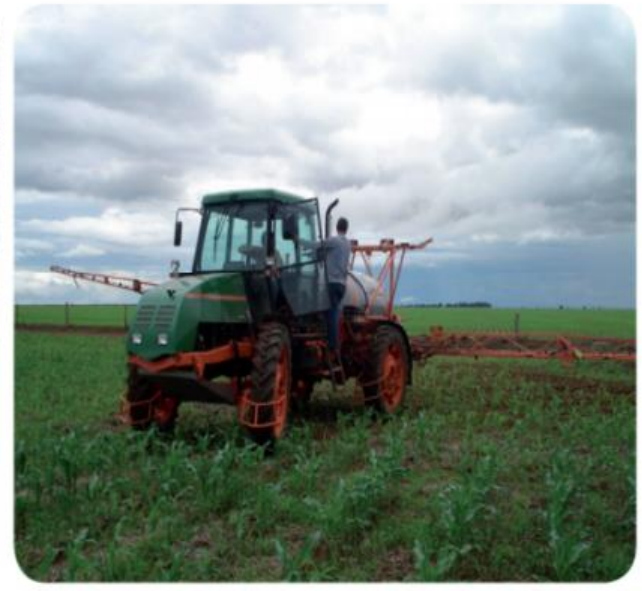

Fazenda em Jatai, Goiás

Fonte: http://projetoseeduc.cecierj.edu.br/eja/materialaluno/modulo01/Miolo_Ciencias_Humanas_Mod01_Vol02_Nova_eja_Aluno.pdf

$\mathrm{Na}$ imagem, observamos um morador em situação de rua, sendo representado por um homem negro, em contrapartida, ao lado, temos uma imagem de um homem branco controlando um trator para exemplificar a modernização do campo brasileiro. Essa situação é um problema político, didático e pedagógico, uma vez que a população negra, mesmo sendo a maioria em território brasileiro e contribuir em vários aspectos na construção desta nação, permanece à margem não só da sociedade, mas também de várias formas de representação. 0 problema principal não é a exposição da imagem acima no material didático, visto que a população negra é a maioria em relação à pobreza no Brasil, mas sim ser a única representação dessa parcela majoritária, sem o contraponto de um lugar positivo que lhe faça jus.

Outro aspecto analisado com resultado negativo sobre a abordagem do conteúdo da Geografia no material - embora não esteja relacionado diretamente à população negra brasileira, porém com conexões passiveis de serem feitas com o passado para se compreender 
o presente-, é a imagem do continente africano sem desenvolvimento, agrário e selvagem. Essa imagem ainda perdura, quando na verdade se quer, ao longo do volume, exemplificar a forma precarizada e não moderna de produzir alimentos agrícolas na África, em contraponto com uma cultura oriental representada por uma mulher, produzindo hortaliças orgânicas como uma nova forma de alimentação mais saudável e moderna. O que temos na imagem é uma cultura e forma de socialização presentes no continente africano expressas de maneira simplista, rupestre e homogênea, como se a única possibilidade de ser fosse aquela, negando, assim, toda a riqueza e diversidade cultural, econômica, política e geográfica desse continente. Observemos:

Figura 4: Exemplificação de tipos de agriculturas nas páginas 110 e 112

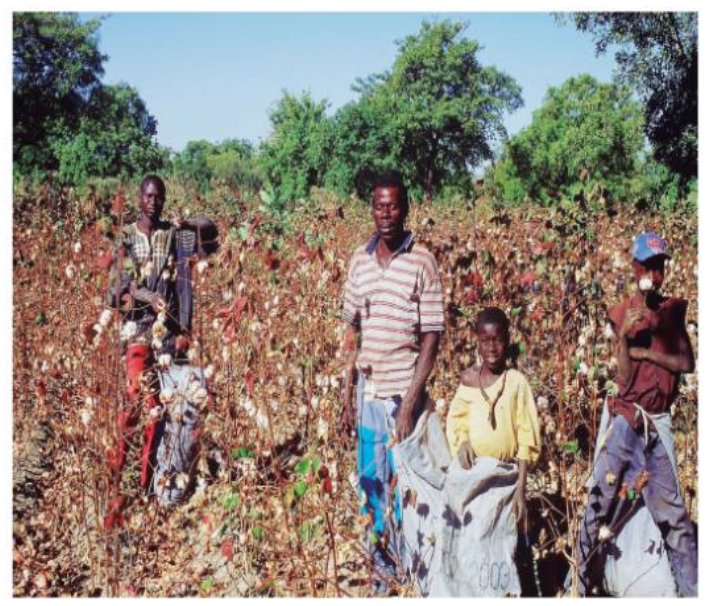

Figura 9: Plantation de algodão.

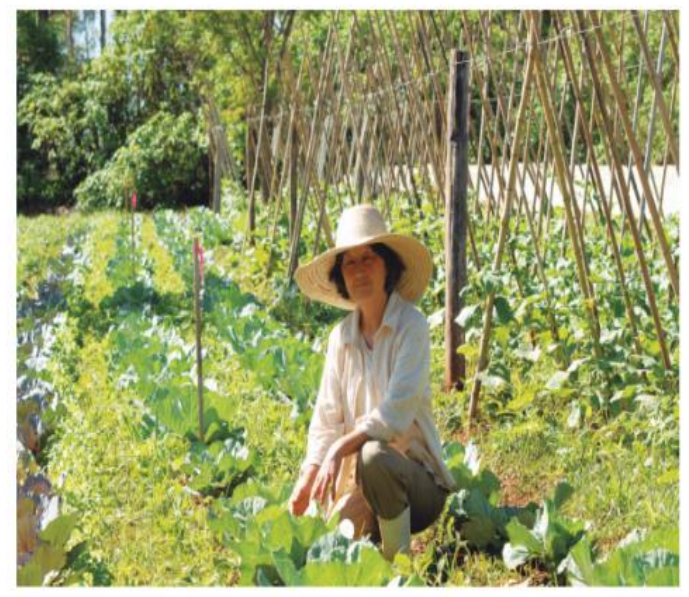

Figura 12: Cultivo orgânico de hortaliças.

Fonte: http://projetoseeduc.cecierj.edu.br/eja/material-aluno/modulo01/Miolo_Ciencias_Humanas_Mod01_Vol02_Nova_eja_Aluno.pdf

Chaves (2006, p.24) saliente que "[...] é necessário melhorar o enfoque dado ao tema África na escola, uma vez que este se encontra diretamente ligado à história do povo afrodescendente no Brasil", pois isso é um ponto central para resgatar a autoestima, o respeito e os direitos básicos dos brasileiros que por muito tempo tiveram o acesso a eles negado.

\section{Conclusões}

Ao longo da história do Brasil, as diferenças têm colocado a população negra no nãolugar, gerando desigualdade e exclusão. É preciso problematizar essa desigualdade no campo 
educacional, em especial na EJA. Discutir a África e a história dos africanos no Brasil é reexistir a uma diferença que gerou e gera exclusão até hoje. E a escola tem um papel central nisso, pois ela tem sido o instrumento principal na função reprodutora de uma cultura que prioriza valorizar e dar visibilidade a uma parte da sociedade em detrimento da outra. E a referida problematização passa por uma postura política, pois é a inversão da lógica oficial já estabelecida e que teima em não ser questionada. É "enegrecer" a geografia, considerar que, ao longo dos séculos, a sociedade brasileira se estruturou a partir do racismo e que cabe, também, aos professores combater essa prática institucional cotidianamente.

Compreender a questão racial e tudo aquilo que a ela está ligada é discutir relação de poder e dominação que permeia tanto a vida fora da escola quanto a cultura escolar. Sendo assim, os docentes que atuam na EJA deverão considerar que a proposta de construção de uma pedagogia que valorize e respeite a identidade negra significa lidar com os conflitos, os confrontos, as contradições e as desigualdades. E isso se faz urgente e necessário, especialmente na EJA, uma vez que é nessa modalidade de ensino que encontramos em maior número o segmento negro e pobre da população.

Essas são questões importantes e passivas de análises no ensino de Geografia. São questionamentos pertinentes que cabem à Geografia colaborar na elaboração de respostas, principalmente em se tratando da EJA, que desde os primórdios da história da educação no Brasil, assim como a população negra, ficou renegada a segundo plano. Portanto, não é por acaso que a EJA tem classe e tem cor: é a classe dos destituídos economicamente, é raça da pele negra. São estudantes de trajetórias truncadas, que tiveram que "abrir mão" da escola para trabalhar e, assim, sobreviver.

Então, amparados pela Lei 10.639/03, que torna obrigatório o ensino da História da África e dos afro-brasileiros, defendemos que esse debate não fique somente circunscrito às disciplinas de História, Artes e Literatura, mas que se estenda aos componentes curriculares de outras disciplinas, como a Geografia, por exemplo.

A referida Lei, fruto da luta dos Movimentos Negros no Brasil, completou 17 anos em janeiro de 2018, após uma década e meia, a referida lei ainda está desequilibrada nos sistemas educacionais. A balança entre as medidas de implementação e a execução na prática pedagógica em sala de aula condena-a ao rol das leis em estados precários de implementação. 
Isso se torna ainda mais grave quando analisamos a Educação de Jovens e Adultos, já que um grande número dos educandos é negro. Tal situação impede reflexões/problematizações das condições de vida dos negros e seus descendentes na sociedade brasileira, dificultando, portanto, a formação de uma força contra hegemônica ao mito da democracia racial e a nãoexposição da desigualdade racial - algo tão necessário para a construção de uma sociedade racialmente equilibrada.

Com isso, temos uma enorme lacuna neste campo, logo a implementação da Lei 10.639/03 precisa ser de fato efetivada pedagogicamente em todas as modalidades de ensino e disciplinas para que alcancemos a desconstrução do mito da democracia racial e a construção de uma educação que, de fato, problematize as Relações Raciais na sociedade brasileira e valorize a cultura afro-brasileira - a fim de que ela fique em "pé" de igualdade com as demais matrizes culturais de formação da cultura brasileira.

Assim, medidas para uma distribuição mais justa do conhecimento são urgentes para que a educação brasileira não se aprisione ao mercado editorial, mas direcione a educação para formação de sujeitos capazes de refletir criticamente sobre o seu papel na sociedade, buscando a equidade social e racial, bem como a quebra de preconceitos tacanhos e inconcebíveis. Vale ressaltar que o mercado editorial tem por premissa ser nacional e, por essa razão, nem sempre os conteúdos abordados dialogam de igual maneira com todos os estudantes do país. Entretanto, o material didático analisado foi produzido exclusivamente para alunos da EJA do estado do Rio de Janeiro e, mesmo assim, ele não consegue dialogar com esses estudantes, uma vez que omite as questões raciais.

O Brasil está reescrevendo a sua história, construindo novos conceitos, olhares, perspectivas históricas e geográficas com o fim de corrigir distorções oriundas da cultura europeia, que foi hegemônica ao longo de vários séculos em nossa sociedade. Nesta perspectiva, a Geografia tem um papel importante, visto que ela instrumentaliza os estudantes para compreenderem a formação do espaço geográfico brasileiro e os povos que contribuíram para essa formação, dentre eles a população negra. Assim, reparar essa dívida social que a sociedade brasileira tem com essa população é necessário, urgente e uma questão de humanidade 


\section{Referências}

ANDRADE, R. C. A educação de jovens e adultos e o programa Nova EJA: um olhar analítico sobre a categoria trabalho para formar trabalhadores. Revista Tamoios [online], v.10, p.35-56, 2014.

ARROYO, M. G. A pedagogia multirracial popular e o sistema escolar. In: GOMES, N. L. (org.). Um olhar além das fronteiras: educação e relações raciais. Belo Horizonte: Autêntica, 2007, p.111-130.

ARROYO, M. G. Educação de jovens e adultos: um campo de direitos e responsabilidade pública. In: SOARES, L.; GIOVANETTI, M. A.; GOMES, N.L. (orgs.). Diálogos na educação de jovens e adultos. Belo Horizonte: Autêntica, 2011, p.19-50.

ARROYO, M. G. Outros sujeitos, outras pedagogias. Petrópolis: Vozes, 2012.

APPLE, M. Cultura e comércio do livro didático. In: APPLE, M. Trabalho docente e textos: economia política das relações de classe e de gênero em educação. Porto Alegre: Artes Médicas, 1995, p.81-105.

CARVALHO, M. B. A natureza na geografia do ensino médio. In: OLIVEIRA, A. U. (org.). Para onde vai o ensino da geografia. São Paulo: Contexto, 1994.

CHAVES, K. S. A representação da África no livro didático de Geografia no ensino fundamental e médio. 2006. 96f. Monografia (Bacharelado em Geografia) - Instituto de Estudos

Socioambientais (IESA), Universidade Federal de Goiás, Goiânia, 2006.

GOMES, N. L. Alguns termos presentes no debate sobre relações raciais no Brasil: uma breve discussão. In: BRASIL. Educação e Anti-racismo: Caminhos Abertos Pela Lei Federal № 10.639/03. Brasília. SECAD/MEC, 2005, p.36-63.

GOMES, N. L. Educação de jovens e adultos e questão racial: algumas reflexões iniciais. In: GOMES, N. L.; SOARES, L.; GIOVANETTI, M. A. (orgs.). Diálogos na educação de jovens e adultos. Belo Horizonte: Autêntica, 2011, p.87-104.

GOVERNO DO ESTADO DO RIO DE JANEIRO. SECRETARIA DE ESTADO DE EDUCAÇÃO DO RIO DE JANEIRO. Manual de Orientações - Nova EJA. 24 p. 2013a. Acessado em 02 de fevereiro 2020. Link: http://projetoseeduc.cecierj.edu.br/eja/manual-eja.pdf

HASENBALG, C. A. Discriminação e desigualdades raciais no Brasil. Belo Horizonte: UFMG; Rio de Janeiro: IUPERJ, 2005.

LIMA, M. História da África: temas e questões para a sala de aula. In: OLIVEIRA, I.; SISS, A. (orgs.). População negra e educação escolar. Caderno Penesb 7, Niterói. Quartet/Eduff, 2006, p.71-105.

Periódico Horizontes - USF - Itatiba, SP - Brasil - e020067 
PONTUSCHKA, N. N. A geografia: ensino e pesquisa. In: CARLOS, A. F. A. (org.). Novos caminhos da geografia. São Paulo: Contexto, 2005, p.111-142.

PONTUSCHKA, N. N.; PAGANELLI, T. I.; CACETE, N. H. Para ensinar e aprender geografia. São Paulo: Cortez, 2007.

PORTO-GONÇALVES, C. W. A Geografia do sistema mundo moderno-colonial numa perspectiva subalterna. In: SANTOS, R. E. (org.). Diversidade, espaço e relações étnico-raciais: o negro na geografia do Brasil. Belo Horizonte: Autêntica, 2007, p.7-11.

SANTOS, S. A. A Lei 10.639/03 como fruto da luta anti-racista do Movimento Negro. In: BRASIL. Ministério da Educação. Secretaria de Educação Continuada, Alfabetização e Diversidade. (orgs.). Educação antirracista: caminhos abertos pela Lei Federal n.10.639/03. Brasília, DF: MEC/SECADI, 2005, p.21-38.

SANTOS, R. E. O ensino de geografia do Brasil e as relações raciais: reflexões a partir da lei 10.639. In: SANTOS, R. E. (org.). Diversidade, espaço e relações étnico-raciais: o negro na geografia do Brasil. Belo Horizonte: Autêntica, 2007, p.21-42.

SANTOS, R. E. O ensino de geografia e a Lei 10.639: algumas discussões de currículo. In: SACRAMENTO, A. C. R.; ANTUNES, C. F.; SANTANNA FILHO, M. M. (orgs.). Ensino de geografia: produção do espaço e processos formativos. Rio de Janeiro: Consequência/FAPERJ, 2015, p.317-339.

VAZOLLER, L. S. As categorias geográficas como fundamentos para os Estudos sobre a População Negra. In: OLIVEIRA, I.; SISS, A. (orgs.). População negra e educação escolar. Caderno PENESB 7. Niterói: Quartet/Eduff, 2006b, p.171-222.

VENTURA, J. P. A oferta de educação de jovens e adultos de nível médio no estado do Rio de Janeiro: primeiras aproximações. Revista Brasileira de Educação de Jovens e Adultos, v.4, n.8, p.9-35, 2016.

WETTSTEIN, G. O que se deveria ensinar hoje. In: OLIVEIRA, A. U. (org.). Para onde vai o ensino de geografia? São Paulo: Contexto, 2005, p.125-134.

Recebido em fevereiro 2020.

Aprovado em agosto 2020. 